\title{
Cytological Evaluation of Pathological Male Breast Lesions
}

\author{
Krishnendu Mondal, (1) Rupali Mandal \\ Department of Pathology, Sonoscan Healthcare, West Bengal, India
}

\begin{abstract}
Objective: This study aimed to determine the cytodiagnostic spectrum of various male breast lesions, which were corroborated on histopathology as appropriate, to describe the process of the cytomorphology of some uncommon pathological lesions, and to discuss the reasons of their misdiagnoses.

Materials and Methods: In this 8-year study, a total of 114 patients underwent fine needle aspiration cytology (FNAC). In a representative case, nipple discharge from an 8-month-old child was examined. Confirmatory histopathology was obtained in 38 cases only.

Results: Gynecomastia was the most common (63.5\%) male breast pathology. Invasive breast carcinoma of no special type was the most common variant of male breast malignancy. Half of the "gray zone" of cytological lesions was confirmed as cancer, but the rest were diagnosed as fibrocystic disease and intraductal papilloma. All cases with malignant cytology matched their corresponding histopathology. However, a tumor from an intraductal papillary carcinoma was miscued as ductal carcinoma on previous FNAC.

Conclusion: Cytological evaluation of male breast lesions provides highly sensitive and specific results with excellent histologic reproducibility. Thus, it should be the ideal pretherapeutic diagnostic procedure for male breasts. However, some benign pathological conditions, which are particularly associated with epithelial hyperplasia, perplex the cytomorphologic scenario into the "gray zone."
\end{abstract}

Keywords: Breast carcinoma, fine needle aspiration cytology, gray zone, gynecomastia, male breast

Cite this article as: Mondal K, Mandal R. Cytological Evaluation of Pathological Male Breast Lesions. Eur J Breast Health 2021; 17(2): 103-111

\section{Key Points}

- Breast pathology is a relatively ignored entity in men, so they are often diagnosed late on the course.

- The most important utility of male breast cytology is to discriminate gynecomastia from any other neoplastic lesions.

- "Gray zone" cytological interpretation is the major pitfall of breast cytology, as it encompasses benign lesions as much as cancerous lesions.

\section{Introduction}

Morphologically, the male breasts, like its female counter organs, consist of glandular and adipose tissues. However, in men, glandular units are composed of ducts only, which are typically circumscribed underneath the nipple-areolar complex (1). Pathological lesions in male breasts are not common. Gynecomastia is the most common lesion in men. Its prevalence varies from $32 \%$ to $65 \%$ with respect to age groups. In postmortem male breast specimens, gynecomastia has been reported in $45 \%-50 \%$ of the cases (2). Similarly, carcinomas rarely occur in male breasts. It accounts for $1 \%$ of all breast cancer cases arising in both sexes, and approximately $1 \%$ of all malignancies occur in men. Clinically, it resembles gynecomastia as well as any other benign pathological lesions associated with male breast enlargement. Therefore, urgent discrimination of these two contrasting pathological entities is necessary (3). For this purpose, core needle biopsy and the recently amended vacuum-assisted breast biopsy are the most useful diagnostic method. However, as the most common male breast pathology, gynecomastia is best cured conservatively; it is therefore unreasonable to consider biopsy as the primary diagnostic intervention. On the contrary, fine needle aspiration cytology (FNAC) provides prompt and precise diagnoses economically and conveniently $(4,5)$. This study aimed to cytologically evaluate various pathological lesions that affect the male breasts and to validate the diagnostic accuracy of FNAC against the histopathology wherever practicable.

\section{Materials and Methods}

This study was approved by the state ethics committee and was accomplished at the Department of Pathology, Sonoscan Healthcare, Malda, India; after acquiring approval from the State Ethics Committee (Ethics Committee Pathology 2010, S1 no: 437/L) on $7^{\text {th }}$ of December, 2010. 
Written informed consent was procured from each patient after explicit explanation of the procedures was provided.

From January 2011 to December 2018, a total of 115 male patients presented with breast lesions. All of them underwent FNAC, except for the 8-month-old infant who was brought for unilateral blood-tinged nipple discharge. The secretion was collected for exfoliative cytology by gentle concentric compression over the nipple. At FNAC, a 24-G disposable needle was utilized. Leishman-Giemsa and Papanicolaou stains were routinely applied for the air-dried and ethanol-fixed smears, respectively. Ziehl-Neelsen $(\mathrm{ZN})$ staining was performed in selective cases. Only 38 patients underwent histopathological corroboration. Statistical analysis was performed in determining the sensitivity, specificity, and positive and negative predictive values of the aspirates.

\section{Results}

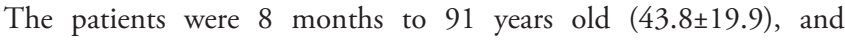
the median age was 48 years. Unilateral involvement of the right and left breasts were observed in 50 and 47 patients, respectively. Eighteen patients had bilateral pathologies. All bilateral lesions were cytologically diagnosed as gynecomastia, except in a single case of fibrocystic changes (FCC). In all patients, gynecomastia was the most common male breast pathology. It was isolated from 73 (63.5\%) cytological samples. Other uncommon benign diagnoses included suppurative mastitis/abscess $(\mathrm{N}=4,3.5 \%)$, tuberculous mastitis $(\mathrm{N}=$
4, 3.5\%), lipoma $(\mathrm{N}=3,2.6 \%)$, benign cyst $(\mathrm{N}=2,1.7 \%)$, chronic nonspecific mastitis $(\mathrm{N}=2,1.7 \%)$, subareolar abscess $(\mathrm{N}=2,1.7 \%)$, fat necrosis $(\mathrm{N}=1,0.9 \%)$, FCC $(\mathrm{N}=1,0.9 \%)$, mammary duct ectasia $(\mathrm{N}=1,0.9 \%)$, and benign papilloma $(\mathrm{N}=1,0.9 \%)$. Of the abovementioned cases, histopathological examination was performed for 16 lumps of gynecomastia, recurrent chronic inflammatory lesion, all cases of lipoma, and benign papilloma (Table 1).

Aspirates from the gynecomastia demonstrated moderate-tohigh cellularity, with numerous tightly cohesive sheets of bimodal epithelial-myoepithelial cells and bipolar nuclei stripped at the background (Figure 1). Of the 73 lumps, 16 were confirmed histologically (Figure 2). The suppurative lesions expressed numerous polymorphs and some histiocytes. Epithelial cells, when present, showed regenerative changes and became barely discernible from the histiocytic clusters. Culture isolated two cases of methicillin-sensitive Staphylococcus aureus and one case each of methicillin-resistant $S$. aureus and Streptococcus pyogenes. Aspirates from the subareolar abscess were characterized by anucleated squames, foreign body-type multinucleated giant cells, neutrophils, and macrophages (Figure 3). Granulomatous syncytial aggregates of epithelioid histiocytes, isolated lymphohistiocytic cells, background caseous necrosis, and presence of acid-fast bacilli on the $\mathrm{ZN}$-stained smears were diagnostic features for tuberculosis. Two of four patients simultaneously suffered from ipsilateral axillary tuberculous lymphadenitis. Calcified healed thoracic foci of old tuberculosis were identifiable in all four cases. Fat

Table 1. Cytological and histopathological distribution of all male breast lesions ( $n=115$ )

\begin{tabular}{|c|c|c|c|}
\hline $\begin{array}{l}\text { Diagnostic } \\
\text { categories }\end{array}$ & $\begin{array}{l}\text { Cytological diagnosis/findings } \\
\text { (Number of cases) }\end{array}$ & $\begin{array}{l}\text { Cases correlated on } \\
\text { histopathology }\end{array}$ & $\begin{array}{l}\text { Histopathogical } \\
\text { diagnosis }\end{array}$ \\
\hline \multirow{4}{*}{$\begin{array}{l}\text { Cystic } \\
\text { (total of } 3 \text { cases) }\end{array}$} & Benign cysts (2) & None & NA \\
\hline & Fibrocystic disease (1) & None & NA \\
\hline & Suppurative mastitis/abscess (4) & None & NA \\
\hline & Tuberculous mastitis (4) & None & NA \\
\hline \multirow{4}{*}{$\begin{array}{l}\text { Inflammatory } \\
\text { (total of } 14 \text { cases) }\end{array}$} & Chronic inflammation (2) & 1 & Lymphocytic mastopathy \\
\hline & Subareolar abscess (2) & None & NA \\
\hline & Fat necrosis (1) & None & NA \\
\hline & Mammary duct ectasia* (1) & None & NA \\
\hline \multirow{3}{*}{$\begin{array}{l}\text { Benign neoplastic } \\
\text { (total of } 77 \text { cases) }\end{array}$} & Gynecomastia (73) & 16 & Gynecomastia \\
\hline & Lipoma (3) & 3 & Lipoma \\
\hline & Benign papilloma (1) & 1 & Intracystic papilloma \\
\hline $\begin{array}{l}\text { Atypical } \\
\text { (total } 4 \text { cases) }\end{array}$ & $\begin{array}{l}\text { Proliferative breast disease with } \\
\text { atypia (4) }\end{array}$ & 4 & $\begin{array}{l}\text { Two cases of invasive breast carcinoma-no special } \\
\text { type, } \\
\text { one each of fibrocystic disease, and intraductal } \\
\text { papilloma }\end{array}$ \\
\hline \multirow{3}{*}{$\begin{array}{l}\text { Malignant } \\
\text { (total of } 12 \text { cases) }\end{array}$} & Ductal carcinoma (10) & 10 & $\begin{array}{l}\text { One case of intraductal papillary carcinoma, } \\
\text { Rest ( } 9 \text { tumors) invasive breast carcinoma-no } \\
\text { special type }\end{array}$ \\
\hline & Metaplastic carcinoma (1) & 1 & Basaloid squamous cell carcinoma \\
\hline & Mucinous carcinoma (1) & 1 & Mucinous carcinoma \\
\hline $\begin{array}{l}\text { Non-diagnostic } \\
\text { (Total of } 5 \text { cases) }\end{array}$ & Adipocytes only & 1 & Gynecomastia \\
\hline
\end{tabular}


necrosis yielded fragments of mature and poly-vacuolated degenerated adipose tissue, foamy macrophages, multinucleated giant cells, and lymphocytes, with a muddy background of granular debris and lipid droplets. No epithelial component was present (Figure 4). Both lesions of chronic nonspecific mastitis yielded scanty lymphocytes and macrophages. One of the lesions was biopsied on recurrence. It featured atrophied ductules mantled immediately by lymphocytic aggregates and further surrounded by dense fibrosis. Therefore, the diagnosis was lymphocytic mastopathy (Figure 5). The patient with FCC complained about bilateral mastalgia. FNAC findings from both breasts appeared fluidy with moderate cellularity. The epithelial aggregates showed mild nuclear enlargement and ample well-defined granular cytoplasm. The background contained many cyst macrophages and some lymphocytes (Figure 6). Both mammary cysts expressed thin mucoproteinaceous fluid with multiple floating

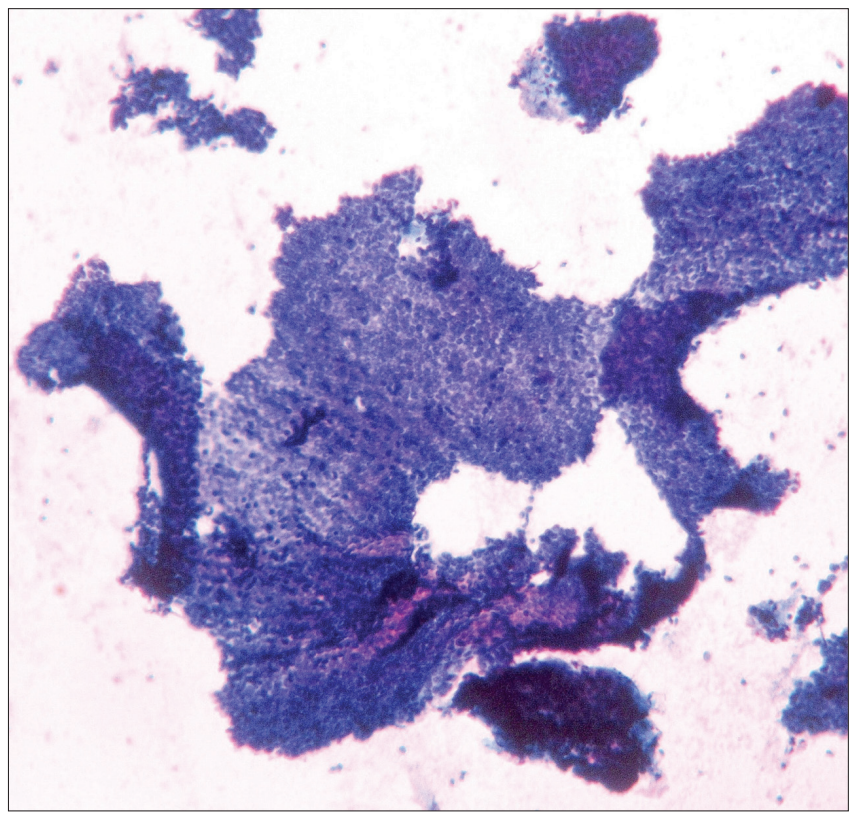

Figure 1. Cytologically, compact folded sheets of benign epithelial cells and stripped bipolar nuclei in gynecomastia (Papanicolaou staining, $\times 40$ )

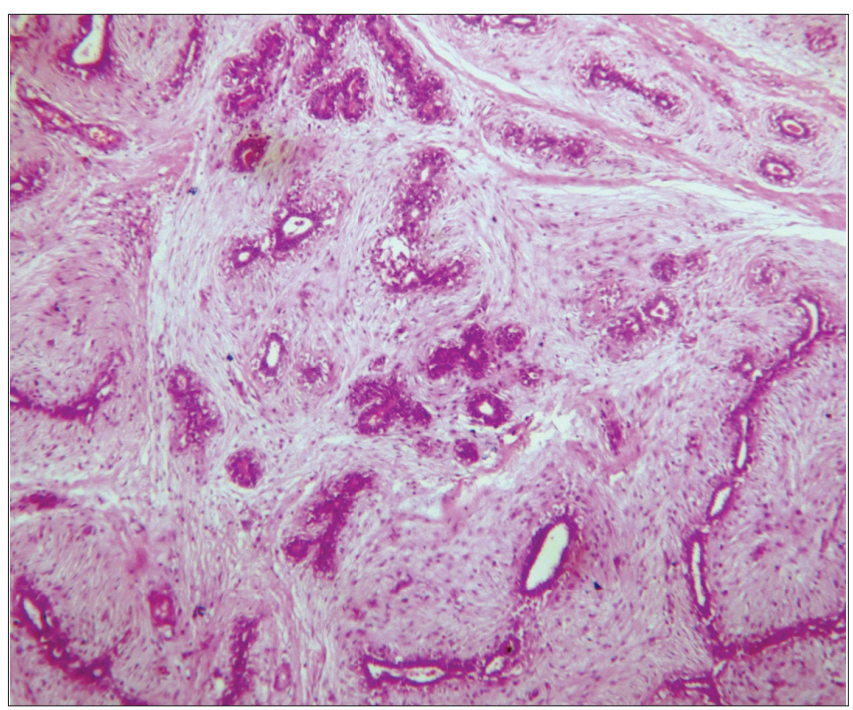

Figure 2. Representative histomorphology of gynecomastia characterized by florid epithelial hyperplasia surrounded by paucicellular fibrotic stroma (hematoxylin-eosin staining, $\times 40$ ) foamy macrophages. Epithelial sheets were observed rarely. The benign papilloma presented as a minute subareolar nodule. On cytological smears, the epithelial cells formed into tightly cohesive complex micropapillary clusters over a background of cyst fluid and stripped nuclei (Figure 7). On histopathology, it was diagnosed as an intracystic papilloma (Figure 8). The infant patient in this study

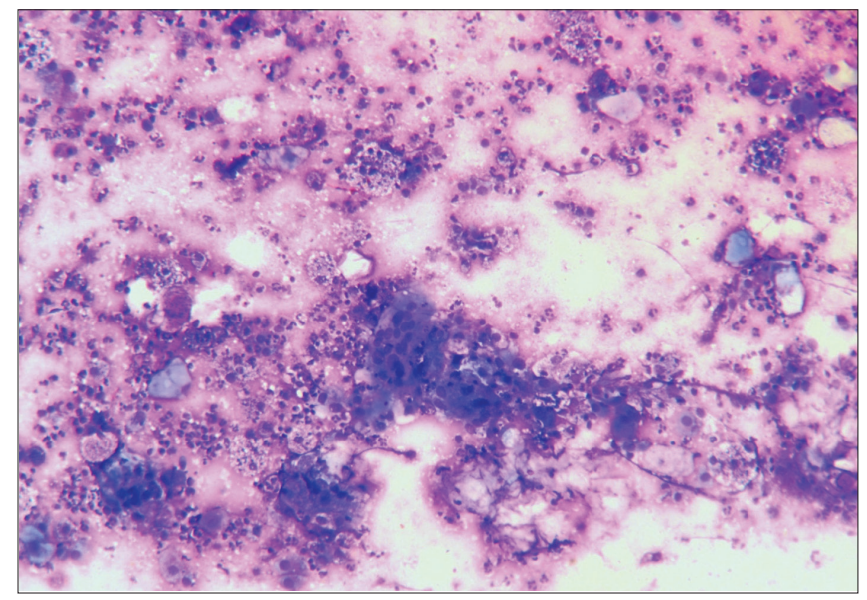

Figure 3. Subareolar abscess on cytology: scattered neutrophils, anucleated squames, and multinucleate giant cells (Leishman-Giemsa staining, $\times 40$ )

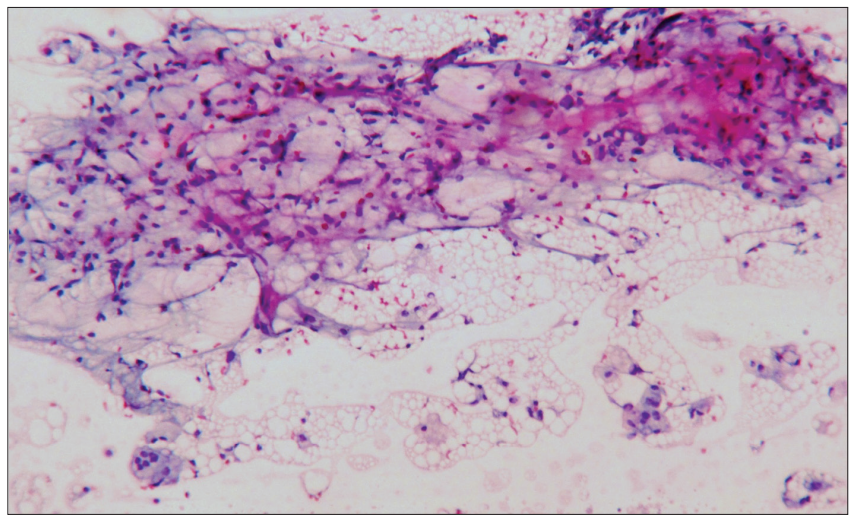

Figure 4. Cytologically, degenerating adipocytic fragments, foamy histiocytes, giant cells, and background fat vacuoles characteristics of fat necrosis (Papanicolaou staining, $\times 40$ )

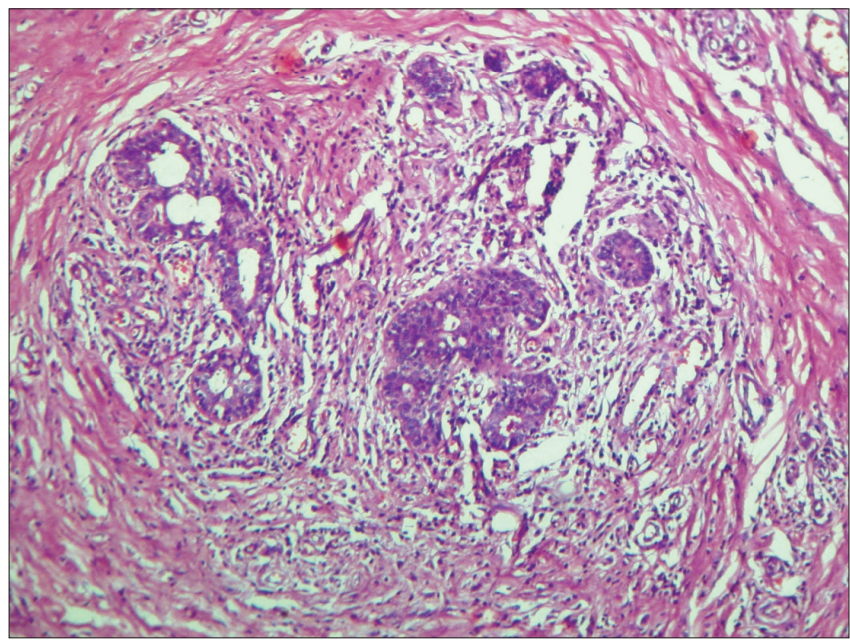

Figure 5. Histology of lymphocytic mastopathy: atrophic ductules surrounded by lymphocytic infiltrates and collagenous fibrosis (hematoxylin-eosin stain, $\times 40$ ) 
was brought with recurring blood-tinged discharge from his right nipple for 2 months. On palpation, any mass defect could not be identified. He had no history of trauma or familial bleeding diathesis. His endocrine activity remained within normal limits. The left breast was symptom-free as well. Nipple secretion was collected by gentle

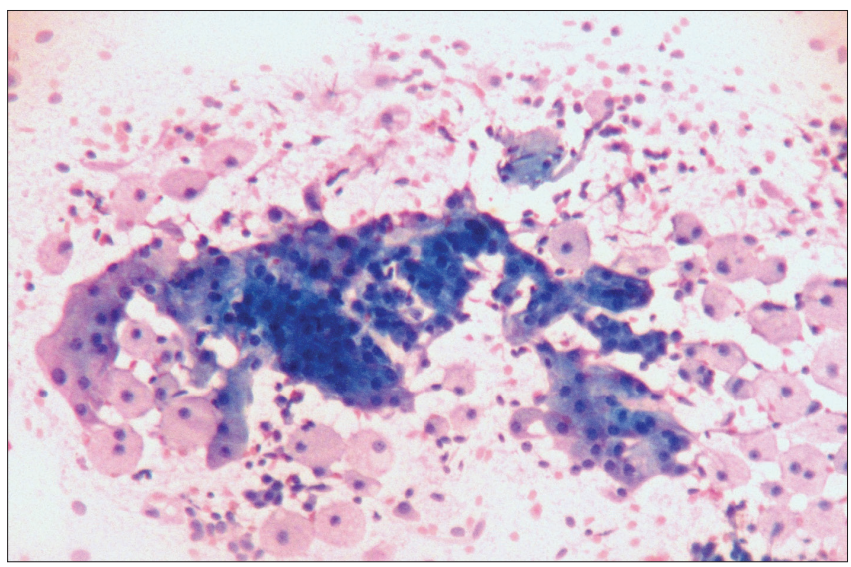

Figure 6. Cytomorphologically, apocrine epithelial changes, cyst macrophages and lymphocytes define fibrocystic changes (Papanicolaou staining, $\times 100$ )

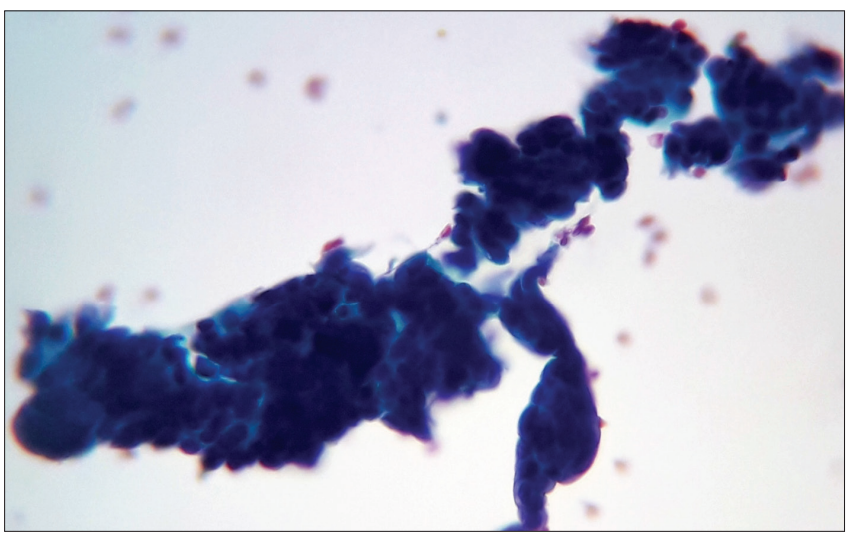

Figure 7. Compact overlapping and arborizing micropapillary fragments of epithelial cells aspirated from benign papilloma (Papanicolaou staining, $\times 400$ )

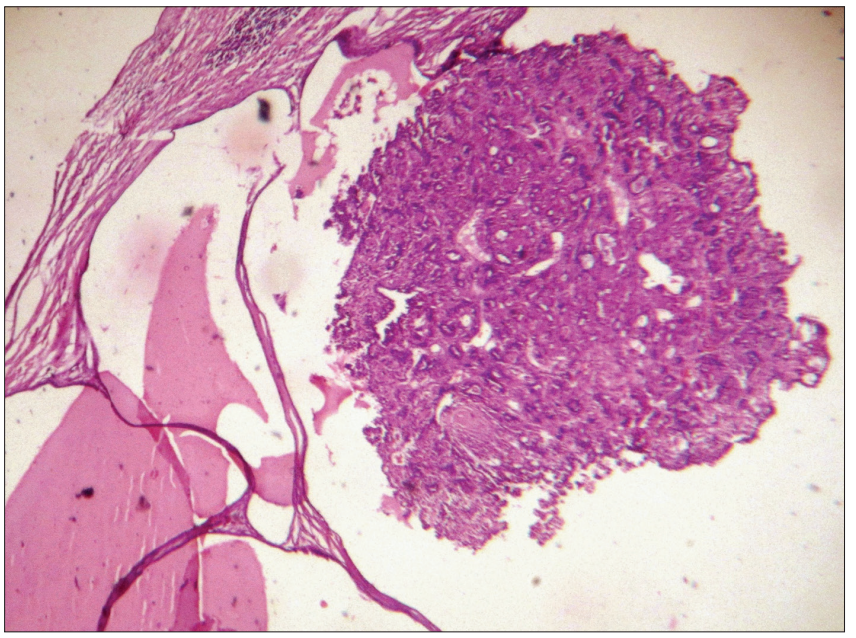

Figure 8. On histology, benign intracystic papilloma presenting as a pedunculated, broad club-like papilla stuffed with numerous manipulation of the right areola. On microscopic examination, the exfoliative cytological smears were populated with siderophages, blood components, proteinaceous debris, and occasional epithelial cells (Figure 9). He was diagnosed with unilateral mammary duct ectasia. During follow-up, the discharge spontaneously tailed off to disappear ultimately within 4 months and did not recur on annual follow-up.

Ductal carcinoma was the most common malignancy, detected cytologically in 10 cases $(8.7 \%)$. The hypercellular smears consisted of discohesive clusters of anaplastic epithelial cells without any bare bipolar nuclei. Four of the patients manifested ipsilateral axillary lymphadenopathy, and another patient presented with multiple subcutaneous metastases over the chest wall. Histopathology confirmed invasive breast carcinoma of no special type (IBCNST) in nine of them, but one was found to have intraductal papillary carcinoma. Samples of a case of metaplastic carcinoma and another case of mucinous carcinoma that metastasized into the ipsilateral cervical lymph node were examined. The mucinous carcinoma yielded abundant stingy mucoid material. Atypical polyhedral epithelial cells appeared to be floating in singles or strips within the pool of extracellular mucin. Tumor cells appeared cytologically bland with prominent nucleoli and abundant cytoplasm. "Chicken-wire" blood vessels were also apparent (Figure 10). Histopathology correlated with the cytodiagnosis of mucinous carcinoma. Cytologically, the metaplastic carcinoma featured cohesive fragments of poorly differentiated malignant epithelial cells. Keratinized squamous cells were sparsely present. Nuclear pyknosis and spindly nuclear contour were also noted sporadically. The background appeared muddy with sufficient necrosis and inflammatory debris (Figure 11). Excision biopsy identified the tumor as basaloid squamous cell carcinoma (SCC) (Figure 12).

Four (3.5\%) of the cases were classified into a less definitive category, as proliferative breast disease with atypia. Hypercellularity, significant nuclear crowding, and overlapping were invariably present in these smears. Additionally, cellular dyshesion, atypia, and scarcity of bipolar

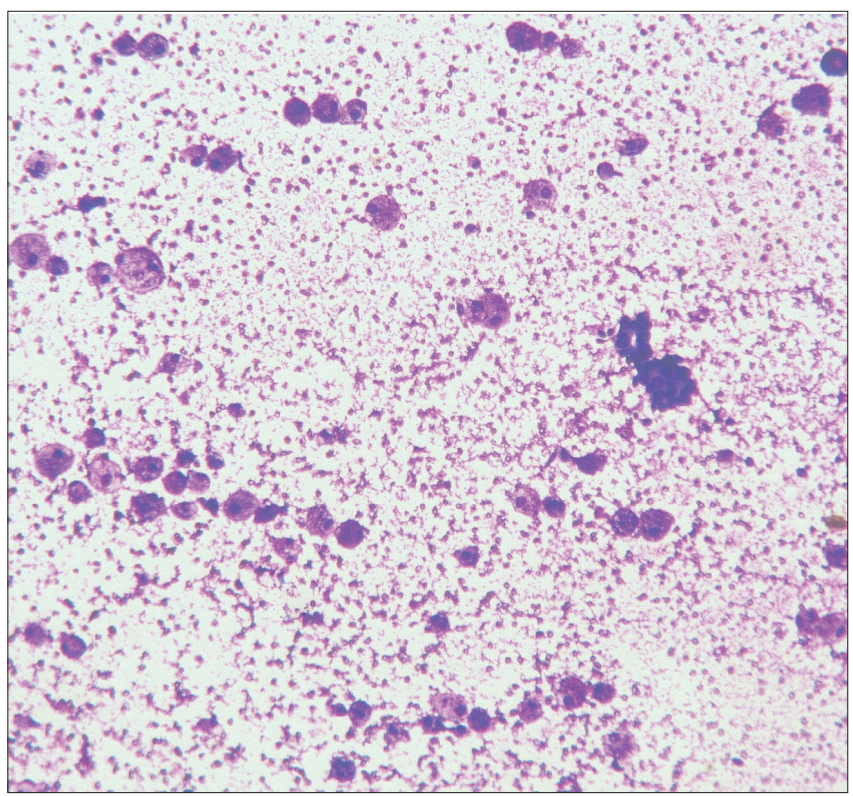

Figure 9. Mammary duct ectasia in an 8-month-old infant expresses siderophages, blood components, and occasional epithelial sheets (Leishman-Giemsa staining, $\times 100$ ) 
nuclei were present (Figure 13). On excision biopsy, two of the cases came out as IBC-NST and the rest as intraductal papilloma (Figure 14) and FCC (Figure 15).

Adequate diagnostic material could not be obtained in five cases (4.3\%) even on repeated attempts. Four of them were treated successfully based on symptomatology. A patient underwent surgical excision, which revealed a gynecomastia. Considering all cases (i.e., benign, atypical, and malignant), no false-positive case was recorded in this study; hence, the sensitivity, specificity, negative predictive value, and positive predictive value were $100 \%, 91.7 \%, 100 \%$, and $87.5 \%$, respectively.

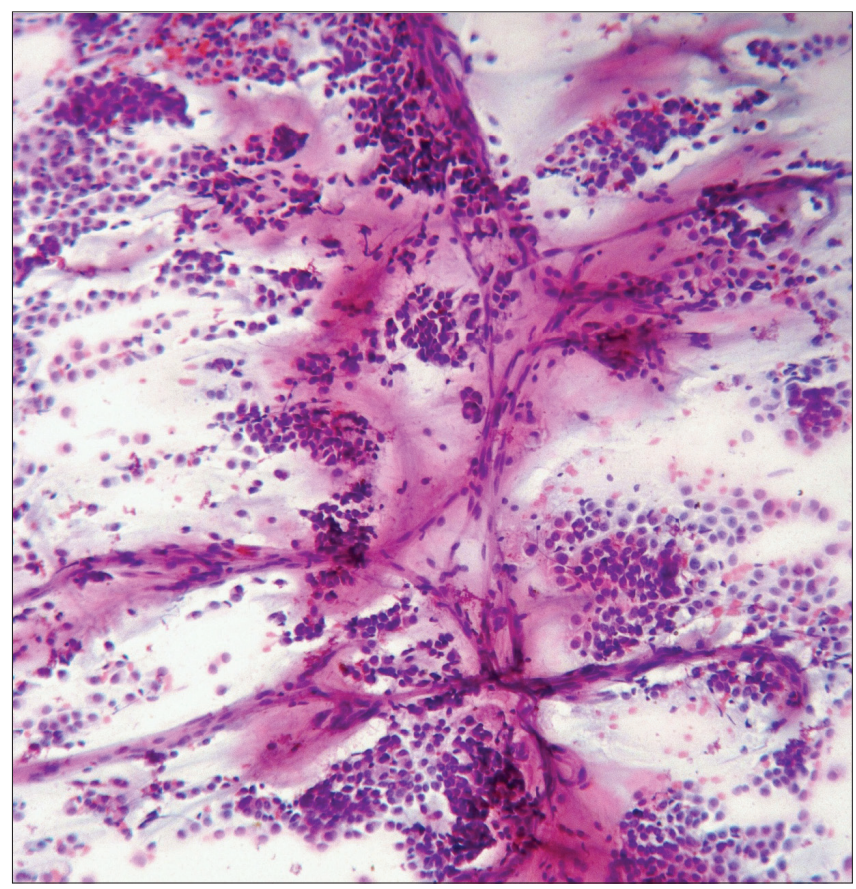

Figure 10. Cytomorphology of mucinous carcinoma: isolated polyhedral malignant cells and "chicken-wire" vascular fragments floating amidst pool of extracellular mucin (Papanicolaou staining, $\times 100)$

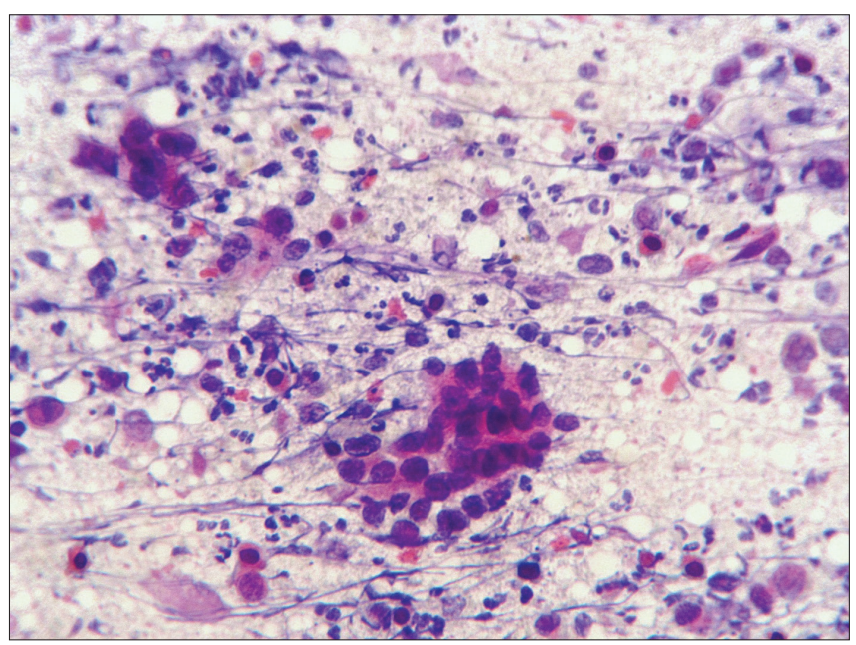

Figure 11. Cytomorphologically, clustered undifferentiated tumor cells within ample necro-inflammatory debris along with welldifferentiated malignant squamous cells featuring nuclear pyknosis and cytoplasmic orangeophilia suggestive of metaplastic breast carcinoma (Papanicolaou staining, $\times 400$ )

\section{Discussion and Conclusion}

Gynecomastia is the most common male breast pathology. Its prevalence, among men with breast-related ailments, varied from $51.2 \%$ to $100 \%$ across the continents $(6,7)$. Asymptomatic gynecomastia is present in $60 \%-90 \%$ of neonates, $50 \%-60 \%$ of adolescents, and up to 70\% of men aged 50-69 years (8). FNAC generally features mild-to-moderate cellular yields. Cytomorphologically, the sheets of bland epithelial cells, bipolar bare nuclei, and stromal fragments resemble the fibroadenoma in women (9). However, unlike fibroadenoma, majority of gynecomastia cases are cured by tamoxifen or raloxifene therapy. Therefore, a pretherapeutic cytological diagnosis of gynecomastia is important to differentiate it from other pathologies that actually need surgery and hence to avert unnecessary operative intervention $(2,8)$.

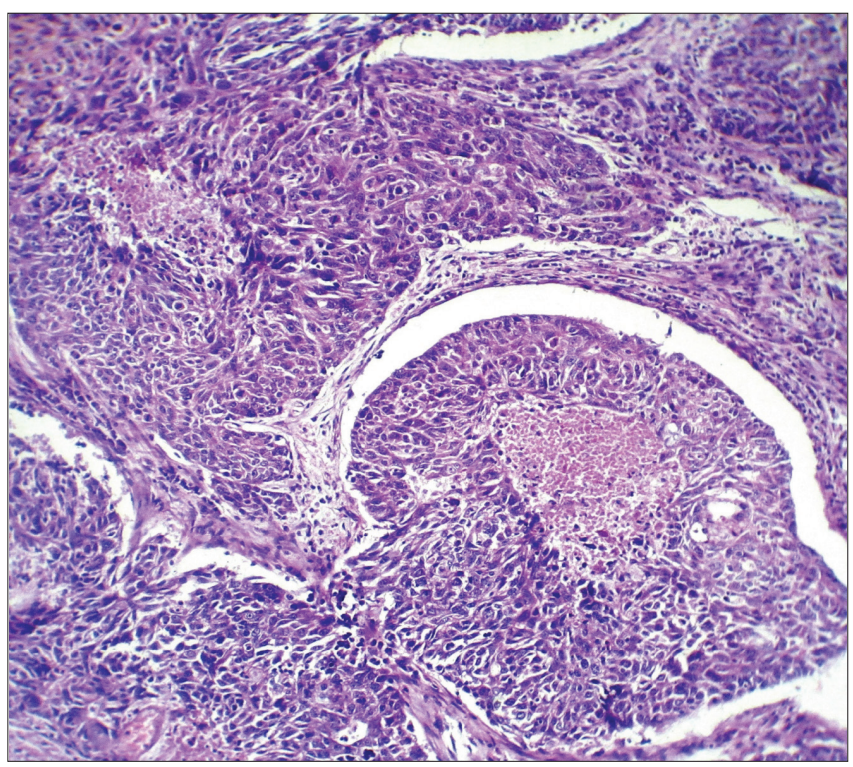

Figure 12. Basaloid variant of squamous cell carcinomarepresentative of the cytodiagnosis of metaplastic carcinoma shown in Figure 11 (hematoxylin-eosin staining, $\times 100$ )

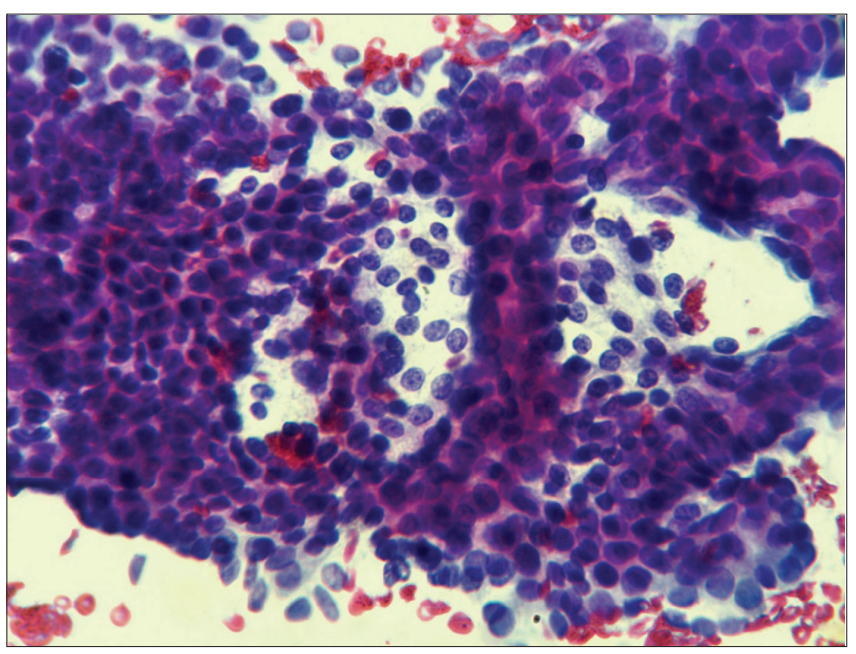

Figure 13. Proliferative breast disease with atypia on cytology: Epithelial cells forming cribriform and crowded overlapping clusters with slight nuclear irregularities, prominent nucleoli (Papanicolaou staining, $\times 400$ ) 
Male breasts are rarely affected by inflammatory lesions. Only $2 \%$ of their pathological conditions result from inflammation (1). Its predisposing factors include decreased immunity, older age, smoking, iatrogenic procedure, trauma, diabetes mellitus (DM), coexistent human immunodeficiency virus infection, overlying skin infection, and alpha-1 antitrypsin deficiency. Common causative organisms are streptococci, staphylococci, and tuberculosis (10). Pyogenic organisms are normal skin inhabitants. They gain access into the breasts either directly through the nipple or extend secondarily from any cutaneous infection $(10,11)$. In this study, four of the lumps were cytologically recognized as suppurative mastitis/abscess. Any history of trauma or pre-existent skin infection was negative. Therefore, retrograde spread via the nipple or secondary extension from any subclinical skin infection likely induced the condition.

India has the highest burden of tuberculosis worldwide, as $27 \%$ of global patients are living here, making prevalence for pulmonary tuberculosis as 295.9 cases per 1 lakh population. Among Indian men, the prevalence is much higher at 418.4 cases per 1 lakh population (12). Still, tuberculous mastitis is a rare disease among Indian men. Given its nonspecific clinical presentation, tuberculous mastitis is often confused with gynecomastia or breast carcinoma at the initial stage. Breasts are only secondarily infected with tuberculosis, even if its primary focus

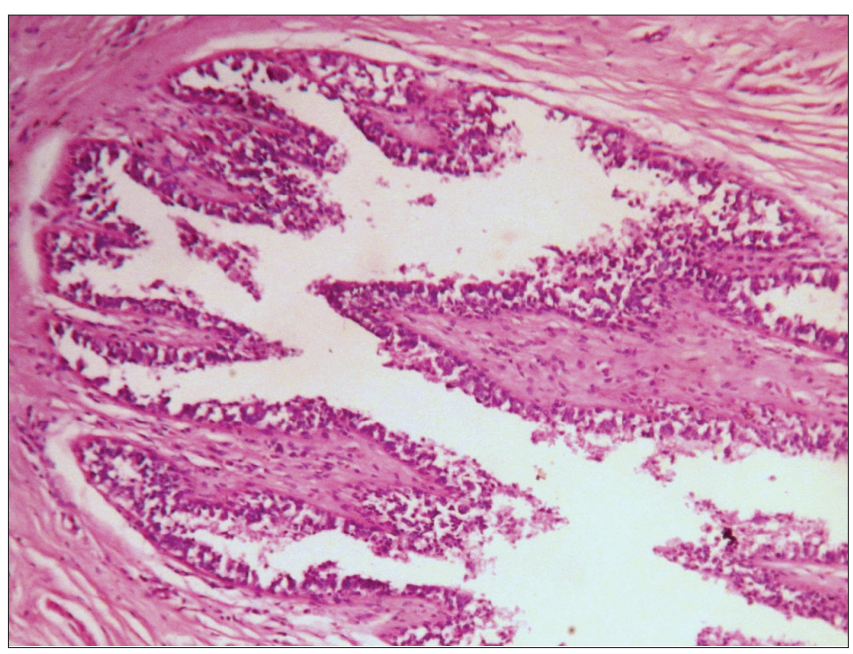

Figure 14. Corresponding histomorphology of an intraductal papilloma: Bilayer epithelial-myoepithelial cells covering the fibrovascular cores (hematoxylin-eosin staining, $\times 40$ )

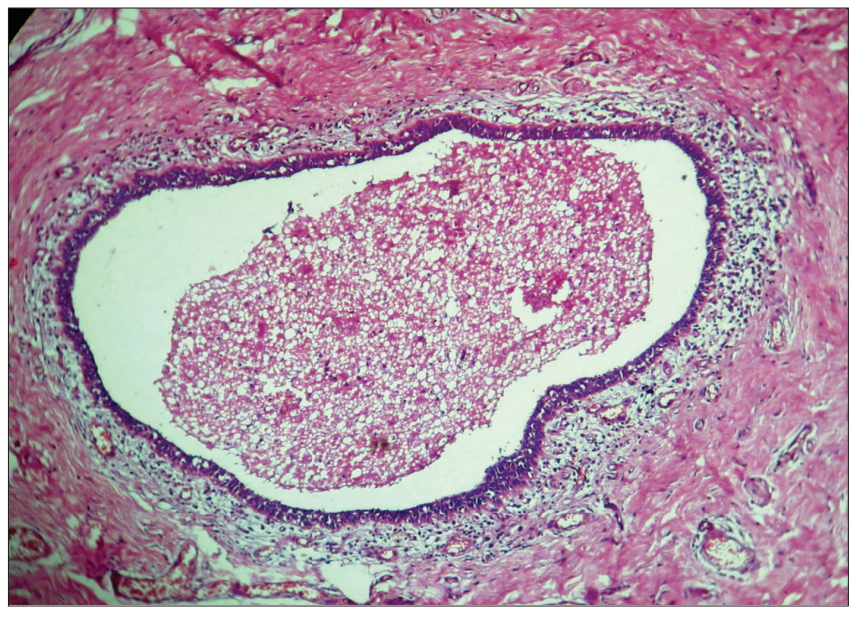

Figure 15. Histology of fibrocystic changes expressing cyst formation remains clinically not apparent (13). Majority of the patients acquire mammary infection through retrograde lymphatic spread via the axillary nodes from any pulmonary primary disease. Similar pathogenic route can also be followed through the tracheobronchial, paratracheal, and cervical lymph nodes. Direct extension from the lungs has also been observed along the involvement of the thoracic bone-cartilage, chest wall, etc., to the breasts. Hematogenous dissemination is mostly observed in patients with human immunodeficiency virus /acquired immune deficiency syndrome (14). In this study, the four patients with tuberculous mastitis belonged to the fragile age cluster of 55-75 years. A calcified focus from previously healed pulmonary tuberculosis was identifiable in each case. Two of the patients were simultaneously suffering from axillary tuberculous lymphadenitis. Cytological demonstration of acid-fast bacilli clinched their diagnosis.

In this study, two cases were cytologically diagnosed as chronic nonspecific mastitis. One of the patients with insulin-dependent DM underwent excision of the lump because of its refractoriness to conventional therapy. On histopathology, it showed ductular atrophy, periductular lymphocytic infiltrates, and dense collagenous fibrosis. Such histomorphology is consistent with lymphocytic mastopathy. This condition is often referred to as diabetic mastopathy due to its predilection for them. However, similar mammary pathology is encountered in other autoimmune disorders, such as systemic lupus erythematosus, Sjogren syndrome, and Hashimoto thyroiditis. It usually occurs in young to middle-aged individuals. Clinicoradiologically, the lumps resembled gynecomastia. No specific cytological features of lymphocytic mastopathy were found. FNAC is indicated for recurrent cases or for monitoring purposes after definitive therapy. Aspirates are generally paucicellular, comprising of clustered benign epithelial cells, lymphocytes, and fibroblastic stromal fragments (14). This case also clinically masqueraded as gynecomastia. FNAC yielded only scant lymphohistiocytic cells without any epithelial cells, which led to the interpretation of chronic nonspecific mastitis. Finally, on histopathology, a definite diagnosis was made.

In this study, lumps were cytologically depicted as proliferative breast disease with atypia. The diagnostic terminology "proliferative breast disease with atypia" represents the "gray zone" in breast cytology. Proper interpretation of this "gray zone" is both difficult and confusing either qualitatively or quantitatively. When the cytological specimen is cellular, with epithelial cells arranged in crowded overlapping groups, with or without any other feature of atypia-like cellular dyshesion or anaplastic changes or scarcity of bare bipolar nuclei, it is predictive of "gray zone" cytomorphology. Pathological lesions amenable to such characterization may range from proliferative fibrocystic disease or sclerosing adenosis to carcinomas $(15,16)$. The National Cancer Institute cytologically classifies the breast lesions as inadequate $(\mathrm{C} 1)$, benign (C2), atypical probably benign (C3), suspected malignancy (C4), and malignant (C5). C3-C4 lesions are equivalent to the "gray zone" cytology, where a straightforward diagnosis is not provided. Histopathological evidence of malignancy is detected in 36\%-52\% of C3 lesions and in 81\%-87.5\% of C4 lesions. Still, many researchers prefer a single equivocal terminology to address both these categories (17). MacIntosh et al. (18) called these lesions collectively as "atypical." The only such lesion from their study was proved to be an invasive ductal carcinoma. In a large study of both male and female patients, Pandya and Shah (16) encountered 21 lesions of proliferative breast disease with atypia, 12 of which were biopsied and $75 \%$ of it came out as ductal carcinoma. In the present study, the "gray zone" lesions were also interpreted as "proliferative breast disease with atypia." 
Histopathology findings confirmed two of these as IBC-NST and one case each of intraductal papilloma and FCC.

Fibrocystic disease is a nonspecific cytodiagnosis. Pathogenically, it originates from lobular units, so the ductules-only male breasts are rarely affected. Its pathogenesis is also poorly understood in men, which can be due to hormonal imbalance, paraneoplastic syndrome, or an idiopathic phenomenon. Most FCC cases were associated with gynecomastia, as bilateral tender and knotty swellings (19). Representative cytological samples display cohesive sheets of benign epithelial cells often featuring apocrine changes, few foamy macrophages, and thin proteinaceous fluid in the background (20). An identical cytomorphology was recapitulated in one of the patients in this study. Upon the diagnosis of bilateral FCC, he was managed conservatively. However, focal epithelial hyperplasia and atypia are commonly associated with FCC. Sometimes, on cytology, these changes appear worrisome to make it indistinguishable from malignancy. Excisional histopathology helps in diagnostic confirmation (21). The same dilemma resurfaced during the study period, as another patient with unilateral FCC was interpreted as having proliferative breast disease with atypia on initial cytology. The classic fibrocystic cytomorphology coexisted along some cell-rich overlapping aggregates of epithelial cells featuring mild nuclear irregularities and occasional mitotic figures. Histology confirmed the lesion as FCC, though some cysts were focally lined by hyperplastic epithelium with marginal nuclear atypia. No evidence of coexistent gynecomastia or any other pathology was detected.

Well-defined cytological features of benign breast papilloma-like fibrovascular stalks covered by columnar cells, large epithelial sheets with ruffled borders, and metaplastic apocrine cells were found. In contrast, other papillary-like proliferations consist of complex bulbous epithelial projections and lack the true fibrovascular cores. Still, on smear examination, difficulty often arises in distinguishing benign papillomas from any other epithelial proliferative lesion or ductal carcinoma. Almost half of the benign papillomas are therefore misdiagnosed cytologically. Smear hypercellularity, scarcity of naked bipolar nuclei, and nuclear pleomorphism are features that seldom help in excluding malignancy, as reactive atypia in papillomatous epithelia commonly play the spoilsport (22). In this study, a similar malignant case of intraductal papilloma was misdiagnosed as proliferative breast disease with atypia. It was then successfully diagnosed and cured by excisional biopsy; however, another case of intracystic papilloma was correctly interpreted on cytology. Intracystic papilloma is simply a morphological variant of intraductal papilloma. If the papillomatous duct appeared dilated and cystic, it is then diagnosed as intracystic papilloma or papillary cystadenoma. However, its treatment policy is different from intraductal papilloma (14).

Milky nipple discharge is common among neonates and infants. This physiological phenomenon is caused by a sudden drop in the level of maternal prolactin and simultaneous persistent high level of fetal prolactin. However, bloody nipple discharge is extremely rare during infancy. Generally, it lacks any association with inflammation, engorgement, or hypertrophy of the breasts. On further exclusion of any drug interaction, bleeding disorder, traumatic exposure, and underlying mass deformity, these cases are attributed to mammary duct ectasia. The specific etiology of infantile duct ectasia remains elusive. Cytology reveals variable numbers of red cells, macrophages, lymphocytes, polymorphs, and epithelial cells. Most cases resolve spontaneously within 6-9 months. Excision should be avoided, as it may cause permanent mammary deformity or dysfunction since an early age (23). Quite differently, in the presented infant, his nipple discharge subsided within 4 months of follow-up. The secretion contained mainly siderophages and blood elements, with occasional epithelial sheets. There was no other underlying pathological or biochemical abnormality as well.

The male breasts presented as the origin of $0.5 \%-1 \%$ of all breast malignancies in both sexes. It is responsible for $<0.1 \%$ of men dying from any malignancy (24). In earlier studies on male breast pathologies, its malignant etiology was recorded in $2.5 \%-28.4 \%$ of the cases ( 1 , $4,7,18,20,25)$. Risk factors include older age, family history of breast cancer, radiation exposure, cryptorchidism, testicular trauma, Klinefelter syndrome, liver disease, and BRCA2 gene mutation. IBCNST is the most common male breast malignancy. It represents approximately $85 \%$ of the cases, and this was followed by papillary carcinoma. Somehow, it occurs more often in men than in women. It constitutes approximately $5 \%$ of all breast cancers in men, compared with $1 \%-2 \%$ in women with breast carcinomas (24). Non-Hodgkin lymphoma, malignant melanoma, oncocytic carcinoma, secretory carcinoma, mucinous carcinoma, and metaplastic carcinoma have been rarely reported $(1,18,20,24-28)$. Metastatic involvement of male breasts with SCC and melanoma are also identified sporadically (26). In this study, a total of 14 cases (12.2\%) of breast carcinoma were detected. Therefore, cytology diagnosed 10 cases as ductal carcinoma, single case each as metaplastic carcinoma and mucinous carcinoma, and two cases as proliferative breast disease with atypia. Under histopathology, a case of ductal carcinoma was confirmed as intraductal papillary carcinoma. This cytological misappropriation for an uncommon subtype of breast carcinoma has been reported quite often in men. Given their extreme rarity compared with conventional IBC-NST, they are easily misdiagnosed as ductal carcinoma on FNAC. The same fallacies were reported by MacIntosh et al. (18) for papillary carcinoma and secretory carcinoma as well as by Pailoor et al. (20) with oncocytic carcinoma.

Metaplastic carcinoma refers to a group of neoplasms that are characterized by the coexistence of adenocarcinoma with metaplastic spindle cells and/or SCC and/or areas of mesenchymal differentiation. As per the World Health Organization classification, metaplastic carcinoma is subclassified as adenosquamous carcinoma, SCC, spindle cell carcinoma, metaplastic carcinoma with mesenchymal differentiation, myoepithelial carcinoma, fibromatosis-like metaplastic carcinoma, and mixed metaplastic carcinoma (29). Histopathologically, its diagnosis is not an issue. However, a confident cytological diagnosis of metaplastic carcinoma remains a hefty task. It requires identification of dual morphology, chondroid stroma, and unequivocal malignant squamous cells or spindle cells. Clustered undifferentiated malignant epithelial cells without keratinization, fragments of amorphous metachromatic substances, atypical spindle cells, and background necrosis are the most consistent cytological findings. Multinucleated tumor giant cells, squamous differentiation, and cuboidal malignant cells are observed sporadically. However, the cytomorphology varies depending on the sampled area and the extent and type of metaplasia, therefore often leading to underdiagnoses or misdiagnoses. Amidst of similar mix-ups, Joshi et al. (30) misinterpreted nine of 10 cytological samples from metaplastic carcinomas during. Such enigma did not appear in the present report. The only case of metaplastic carcinoma expressed clusters of undifferentiated malignant epithelial cells and necro-inflammatory debris, alongside the presence of orangeophilic keratinized squamous cells that provided its definite diagnosis on 
FNAC. Histopathology confirmed the tumor as basaloid SCC, without any adenocarcinoma component or mesenchymal differentiation.

In conclusion, this latest study reinstitutes the pretherapeutic utility of cytological examination in the management of pathological male breast lesions. Its major drawback present when any benign condition is associated with epithelial hyperplasia and thus expresses hypercellularity and nuclear crowding-overlapping and atypia, with scarce bipolar bare nuclei. Cytodiagnostically, such lesions are included to the quasi-specific "gray zone" category. Biopsy is mandatory for their proper classification. On a minor defection, rare subtypes of male breast cancers are often barely discernible from the conventional ductal carcinoma on cytology. Although it is of lesser importance, their individual treatment protocol is not different.

Ethics Committee Approval: This study was approved by the state ethics committee and was accomplished at the Department of Pathology, Sonoscan Healthcare, Malda, India; after acquiring approval from the State Ethics Committee (Ethics Committee Pathology 2010, S1 no: 437/L) on $7^{\text {th }}$ of December, 2010.

Informed Consent: Written informed consent was procured from each patient after explicit explanation of the procedures was provided.

Peer-review: Externally peer-reviewed.

\section{Authorship Contributions}

Conception: K.M., R.M.; Design: R.M.; Supervision: R.M.; Materials: K.M.; Data Collection or Processing: R.M.; Analysis or Interpretation: K.M.; Literature Search: R.M.; Writing: K.M.; Critical Review: R.M.

Conflict of Interest: No conflict of interest was declared by the authors.

Financial Disclosure: The authors declared that this study received no financial support.

\section{References}

1. Singh R, Anshu, Sharma SM, Gangane N. Spectrum of male breast lesions diagnosed by fine needle aspiration cytology: A 5-year experience at a tertiary care rural hospital in central India. Diagn Cytopathol 2012; 40: 113-117. (PMID: 22246926) [Crossref]

2. Cuhaci N, Polat SB, Evranos B, Ersoy R, Cakir B. Gynecomastia: Clinical evaluation and management. Indian J Endocrinol Metab 2014; 18: 150158. (PMID: 24741509) [Crossref]

3. Chikaraddi SB, Krishnappa R, Deshmane V. Male breast cancers in Indian patients: Is it the same? Indian J Cancer 2012; 49: 272-276. (PMID: 23238143) [Crossref]

4. Wauters CAP, Kooistra BW, de Kievit-van der Heijden IM, Strobbe LJA. Is cytology useful in the diagnostic workup of male breast lesions? A retrospective study over a 16-year period and review of the recent literature. Acta Cytol 2010; 54: 259-264. (PMID: 20518408) [Crossref]

5. Rosa M, Masood S. Cytomorphology of male breast lesions: Diagnostic pitfalls and clinical implications. Diagn Cytopathol 2012; 40: 179-184. (PMID: 22246937) [Crossref]

6. Al-Allak A, Govindarajulu S, Shere M, Ibrahim N, Sahu AK, Cawthorn SJ. Gynaecomastia: A decade of experience. Surgeon 2011; 9: 255-258. (PMID: 21843819) [Crossref]

7. Jatav J, Gaur R, Pandit V, Jain B. Cytological evaluation of male breast lesions in greater Gwalior: A five year retrospective study. J Evid Based
8. Johnson RE, Kermott CA, Murad MH. Gynecomastia - Evaluation and current treatment options. Ther Clin Risk Manag 2011; 7: 145-148. (PMID: 21479145) [Crossref]

9. Chide PM, Nayak S, Kumbhalkar D. Role of fine needle aspiration cytology in male breast lesion: 4 year observational study. Int J Res Med Sci 2016; 4: 3945-3950. [Crossref]

10. Gochhait D, Dehuri P, Umamahesweran S, Kamat R. Breast abscess mimicking breast carcinoma in male. J Midlife Health 2018; 9: 39-40. (PMID: 29628728) [Crossref]

11. Iuanow E, Kettler M, Slanetz PJ. Spectrum of disease in the male breast. AJR Am J Roentgenol 2011; 196: W247-W259. (PMID: 21343472) [Crossref]

12. Sathiyamoorthy R, Kalaivani M, Aggarwal P, Gupta SK. Prevalence of pulmonary tuberculosis in India: A systematic review and meta-analysis. Lung India 2020; 37: 45-52. (PMID: 31898620) [Crossref]

13. Quaglio G, Pizzol D, Bortolani A, Manenti F, Isaakidis P, Putoto G, et al. Breast tuberculosis in men: A systematic review. PLoS One 2018; 13: e0194766. (PMID: 29614082) [Crossref]

14. Hoda SA, Brogi E, Koerner FC, Rosen PP. Rosen's breast pathology. 4th ed. Philadelphia: Lippincott Williams \& Wilkins; 2014.

15. Mihalache D, Giuşcă SE, Balan R, Amălinei C, Grigoraş A, Căruntu ID, A morphometric approach in breast cytology - Geometrical descriptors in the differentiation between benign and malignant lesions. Rom J Morphol Embryol 2014; 55: 273-277. (PMID: 24969974) [Crossref]

16. Pandya AN, Shah NP. Breast fine needle aspiration cytology reporting: A study of application of probabilistic approach. Ind Med Gaz 2013; 147: 54-59. [Crossref]

17. Arul P, Masilamani S, Akshatha C. Fine needle aspiration cytology of atypical (C3) and suspicious (C4) categories in the breast and its histopathologic correlation. J Cytol 2016; 33: 76-79. (PMID: 27279682) [Crossref]

18. MacIntosh RF, Merrimen JL, Barnes PJ. Application of the probabilistic approach to reporting breast fine needle aspiration in males. Acta Cytol 2008; 52: 530-534. (PMID: 18833813) [Crossref]

19. Ramji AN. Fibrocystic disease of the male breast: A case report and literature review of the rare entity. Int J Med Rev Case Rep 2019; 3: 533534. [Crossref]

20. Pailoor K, Fernandes H, Cs J, Marla NJ, Keshava SM. Fine needle aspiration cytology of male breast lesions - A retrospective study over a six year period. J Clin Diagn Res 2014; 8: FC13-FC15. (PMID: 25478347) [Crossref]

21. Robertson KE, Kazmi SA, Jordan LB. Female-type fibrocystic disease with papillary hyperplasia in a male breast. J Clin Pathol 2010; 63: 88-89. (PMID: 20026704) [Crossref]

22. Shabb NS, Boulos FI, Abdul-Karim FW. Indeterminate and erroneous fine-needle aspirates of breast with focus on the 'true gray zone': A review. Acta Cytol 2013; 57: 316-331. (PMID: 23860443) [Crossref]

23. Nascimento M, Portela A, Espada F, Fonseca M. Bloody nipple discharge in infancy-Report of two cases. BMJ Case Rep 2012; 2012: bcr2012006649. (PMID: 22814989) [Crossref]

24. Yitta S, Singer CI, Toth HB, Mercado CL. Sonographic appearances of benign and malignant male breast disease with mammographic and pathologic correlation. J Ultrasound Med 2010; 29: 931-947. (PMID: 20498468) [Crossref]

25. Hoda RS, Arpin III RN, Gottumukkala RV, Hughes KS, Ly A, Brachtel EF. Diagnostic value of fine-needle aspiration in male breast lesions. Acta Cytol 2019; 63: 319-327. (PMID: 30904908) [Crossref]

26. Tangerud A, Potapenko I, Skjerven HK, Stensrud MJ. Radiologic evaluation of lumps in the male breast. Acta Radiol 2016; 57: 809-814. (PMID: 26543053) [Crossref] 
27. Barr JG, Clayton ESJ, Sotheran W. A case of metaplastic breast cancer in a man. J Surg Case Rep 2013; 2013: rjs047. (PMID: 24964410) [Crossref]

28. Ingle AP, Kulkarni AS, Patil SP, Kumbhakarna NR, Bindu RS. Mucinous carcinoma of the male breast with axillary lymph node metastasis: Report of a case based on fine needle aspiration cytology. J Cytol 2012; 29: 7274. (PMID: 22438625) [Crossref]
29. WHO classification of tumours editorial board, editors. WHO classification of tumours: Breast tumours. 5th ed, vol 2. Lyon: IARC Press; 2019.

30. Joshi D, Singh P, Zonunfawni Y, Gangane N. Metaplastic carcinoma of the breast: Cytological diagnosis and diagnostic pitfalls. Acta Cytol 2011; 55: 313-318. (PMID: 21791899) [Crossref] 